\title{
ATUAÇÃO DOS SISTEMAS DE FORÇAMENTO NOS SISTEMAS TERRESTRES A PARTIR DA AÇÃO ANTRÓPICA
}

\author{
Estevão Botura Stefanuto ${ }^{(a)}$, Cenira Maria Lupinacci ${ }^{(b)}$ \\ (a) Departamento de Planejamento Territorial e Geoprocessamento (DEPLAN), UNESP - Rio Claro, \\ estevao1508@hotmail.com \\ (b) Departamento de Planejamento Territorial e Geoprocessamento (DEPLAN), UNESP - Rio Claro, \\ cenira@rc.unesp.br
}

EIXO: SISTEMAS GEOMORFOLÓGICOS: ESTRUTURA, DINÂMICAS E PROCESSOS

\begin{abstract}
Resumo
A modificação da superfície terrestre se intensificou nas últimas décadas, fazendo com que se suscitasse a designação de um novo período geológico intitulado de Antropoceno. Com isso, a busca dos sistemas terrestre por uma auto-organização foi alterada mediante a atuação de sistemas de forçamento, responsáveis por tornarem complexas as respostas de um determinado sistema. Visando dialogar com tal complexidade, buscar-se-á com este artigo apresentar os dados de uso e ocupação da terra, assim como os geomorfológicos de dois recortes espaciais do setor cuestiforme de Analândia (SP), nos quais algumas drenagens e uma feição linear do tipo voçoroca apresentaram respostas não lineares mediante a atuação de sistemas de forçamento. Assim, através de tal análise, foi possível verificar que a atuação de sistemas de forçamento de origem antrópica, faz com que alguns conjuntos apresentem dificuldades em atingir sua auto-organização, e passem assim a emitir respostas não lineares e de difícil previsibilidade.

Palavras-chave: Geomorfologia, antropogeomorfologia, sistemas de forçamento, sistemas complexos.
\end{abstract}

\section{Introdução}

O ser humano, desde suas primeiras organizações sociais, passou a correlacionar-se com a natureza, considerando-a como um dos principais elementos a serem dominados. Assim, no século XVII com o alvorecer da ciência moderna (CHAUI, 1994), no final do século XVII e início do século XVIII com a Revolução Industrial (HOBSBAWM, 1981), e com a intensa expansão da população mundial em meados do século XX (TREWARTHA, 1974), a relação de dominação e transformação do ser humano para com o sistema natural se intensificou, fazendo com que, segundo Casseti (1991), as demandas não fossem somente por elementos primordiais à manutenção da vida humana, mas que, através do trabalho, se buscasse ampliar o poderio humano sobre natureza.

Assim, com o auxílio de diversos ramos da ciência o ser humano buscou o desenvolvimento de suas demandas junto ao espaço natural, chegando para alguns autores, do ponto de vista do relevo, a ser denominado como um novo agente geomorfológico.

Nem toda intervenção humana é direcionada contra os processos naturais. Algumas podem seguir sua direção, meramente mudando seu ritmo. Isso é o suficiente para abalar o estado de equilíbrio dinâmico (...). A maioria das atividades do homem 


\section{OS DESAFIOS DA GEOGRAFIA FÍSICA NA FRONTEIRA DO CONHECIMENTO \\ Instituto de Geociências - Unicamp Campinas - SP \\ 28 de Junho à 02 de Julho de 2017}

pertence à áreas pequenas, seja em áreas densamente construídas, escavações de minas abertas, rodovias em construção, ou rios sendo represados. Essas atividades, quando comparadas com aquelas de processos naturais, são, entretanto, altamente intensas. Seu impacto por unidade de área é muitas vezes maior que dos processos naturais. (NIR, 1983, p. 13 e 14, tradução nossa).

Zalasiewicz et. al. (2016) afirma ainda que as mudanças no sistema terrestre podem ocorrer também através da deposição de diferentes materiais de origem antrópica, intitulados de sedimentos artificiais, que seriam compostos por lama e areia misturados com materiais sintéticos como o plástico. Para os autores, o ser humano já produziu, mesmo em um curto período de tempo, sedimentos e geleiras com características distintas das que compõe o Holoceno, fomentando assim o surgimento de uma nova era geológica na tabela cronoestratigráfica, intitulada de Antropoceno.

Com terminologia distinta, mas reforçando a teoria apresentada por Zalasiewicz et. al. (2016), Peloggia (1998) afirma que com a evolução humana surgiram inúmeras formas de urbanização e de produção agrícola, que atualmente atingem um estágio de modificação da paisagem que ultrapassa os limites dos processos naturais geomorfológicos e geológicos, chegando a suscitar a designação de um novo período geológico: o Quinário ou Tecnógeno.

Já para Ellis (2011) a superfície terrestre, mediante a ação antrópica, atingiu um estágio de modificação elevada, ao qual a subdivisão do planeta em biomas não é mais possível. Assim, o autor sugere a terminologia antroma, justificando que um bioma seria algo natural e que apresenta continuidade, características, que, devido ao uso da terra e da densidade populacional, não são mais encontradas na natureza.

Assim, compreendendo a complexidade que as ações humanas agregam aos sistemas naturais, Murray et. al. (2009) apresenta que os sistemas naturais buscam uma auto-organização, que pode sofrer interferências de sistemas de forçamento, sejam esses de origem natural ou antrópica. A partir da atuação dos sistemas de forçamento, um sistema natural poderá apresentar respostas não lineares, dificultando assim a capacidade de previsibilidade dos seres humanos no que se refere as suas respostas. Murray et. al. (2009) aponta também um questionamento em relação às mudanças atuais nos sistemas terrestres, discutindo se essas são provenientes de sistemas de forçamento naturais ou antrópicos.

Visando dialogar com as questões apresentadas, buscar-se-á com este artigo apresentar dois recortes espaciais do setor cuestiforme de Analândia (SP), nos quais algumas drenagens e uma feição linear do tipo voçoroca apresentaram, durante o período analisado, respostas não lineares mediante a atuação de sistemas de forçamento. Para fundamentar o estudo, buscando uma análise comparativa, foram confeccionados mapas de uso da terra dos anos de 1962, 1988 e 2010, sendo os mesmos analisados comparativamente com as informações dos mapeamentos geomorfológicos desenvolvidos por Stefanuto e Lupinacci (2016), no mesmo setor e período de análise aqui propostos. 


$\begin{aligned} & \text { XVII Simpósio Brasileiro } \\ & \text { de Geografia Fisica Aplicada }\end{aligned}$
$\begin{aligned} & \text { ICongresso Nacional } \\ & \text { de Geografia Física }\end{aligned}$

Pondera-se que a área de estudo foi delimitada em função do setor do relevo de cuetas do Estado de São Paulo correspondente à Serra do Cuscuzeiro (Figura 1), uma vez que, apresenta alta complexidade e relevância para os estudos geomorfológicos. Assim, os limites procuram abarcar o front da cuesta $\mathrm{e}$ seu tálus, até as nascentes dos cursos d'água que se posicionam no reverso e que tem relevante papel na esculturação do referido front.

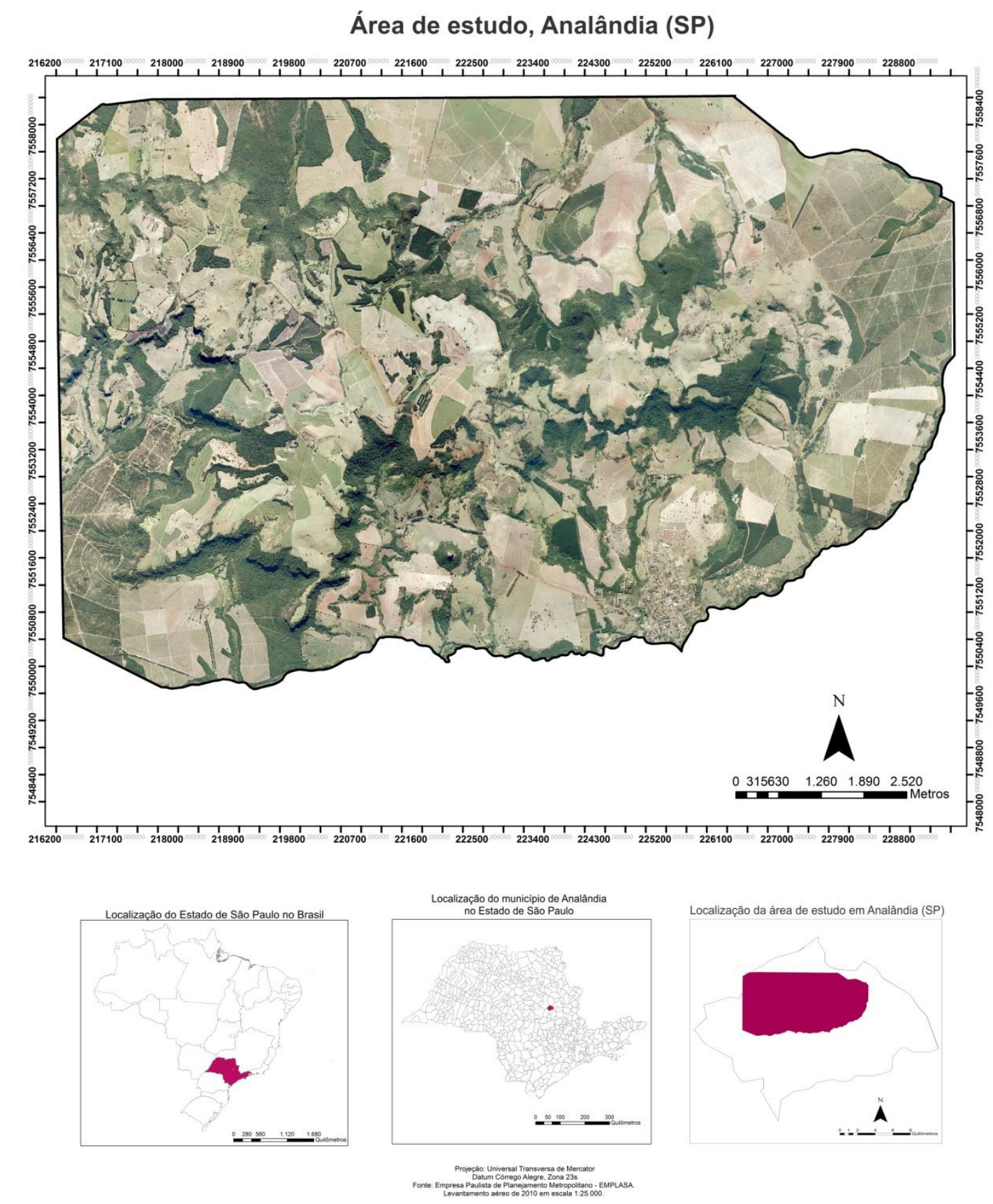

Figura 1 - Localização da área de estudo

Destaca-se ainda que a área deste estudo apresenta intensa atuação antrópica sobre as formas de relevo, onde o uso agrícola evidencia-se em franca expansão desde meados da década de 1960. De 
1960 até o presente momento, variados setores, como a bacia do Córrego Cavalheiro, sofreram diversos usos como: pastagens (pasto limpo e pasto sujo) e cultivos de cana de açúcar, pinus e eucalipto (PINTON, 2011).

\section{Material e Método}

Os mapeamentos de uso da terra foram gerados a partir de levantamentos aerofotogramétricos, sendo as fotografias aéreas 1962, em escala aproximada de 1:25.000, adquiridas junto ao Instituto Agronômico de Campinas; as de 1988, em escala aproximada de 1:40.000, obtidas junto ao acervo de fotografias aéreas do DEPLAN/IGCE; e as de 2010, em escala aproximada de 1:25.000, obtidas via requerimento enviado a Empresa Paulista de Planejamento Metropolitano (EMPLASA).

O referido mapeamento foi formulado através do software ArcGis 9.2.

Os mapeamentos de uso da terra foram desenvolvidos conforme proposta do IBGE (2013), levando em consideração as etapas de interpretação; edições temáticas ou reinterpretações; legenda dos padrões; mapa final; edição cartográfica e legenda de cores e simbologias; e a adição de complementos.

No que se refere à fotointerpretação, utilizou-se nesta pesquisa a proposta de Ceron e Dinis (1966), visto que os autores apresentam algumas chaves que facilitam a identificação de determinadas culturas e a compreensão de algumas variáveis como cor, textura, restos da colheita, dimensão da área cultivada e altura dos objetos mapeados.

Buscou-se ainda um aumento na qualidade da interpretação dos pares estereoscópicos de fotografias aéreas através da técnica intitulada anáglifo, que garante, segundo Souza e Oliveira (2012) a sobreposição de fotografias estereoscópicas em cores complementares (azul-esverdeado e vermelho), que com o uso de óculos 3D, permitem a percepção de profundidade. Para tal, foi utilizado o software de uso gratuito StereoPhoto Maker 4.34.

Assim, os mapeamentos de uso e ocupação da terra foram elaborados e seus dados quantificados.

Buscando atender ao objetivo proposto, utilizaram-se os dados geomorfológicos da área apresentados por Stefanuto e Lupinacci (2016), os quais permitiram uma análise comparativa com as informações de uso da terra elaboradas nesta pesquisa, possibilitando assim uma maior fundamentação na discussão dos dados.

\section{Resultados e Discussões}

A área de estudo deste artigo consiste em terrenos que se caracterizam pelo contato entre o compartimento Depressão Periférica Paulista e as Cuestas Basálticas, que dão origem a intitulada por 
Christofoletti e Queiroz Neto (1961), Serra do Cuscuzeiro, localizada em Analândia (SP). Este setor constitui-se ainda, de acordo com Stefanuto e Cunha (2015a), em uma área de alta complexidade na qual é registrada a ocorrência de quebra de energia de fluxo em trechos de alguns córregos; setores de expressivo estreitamento das linhas de cumeada, provenientes da atuação de canais fluviais; e a presença, segundo Stefanuto e Cunha (2015b), de lineamentos que chegam a afetar até $1500 \mathrm{~m}$ de trajetos fluviais. Assim, a área aqui apresentada possui, segundo Stefanuto e Lupinacci (2016), relevo de alta complexidade e setores com topografia acidentada, além de, segundo Pinton (2011), constituirse em um setor de franca expansão agrícola, com a consolidação, a partir de 1988, de áreas de pastagem e cana-de-açúcar em maior relevância.

Buscando compreender a complexidade presente na Serra do Cuscuzeiro, apresenta-se no decorrer desta seção dois setores nos quais as mudanças em uma feição erosiva linear e em alguns canais fluviais são complexas, correlacionando ainda as referidas alterações com a interferência antrópica representada pelo uso e ocupação da terra.

De acordo com Ayres (1960), em função da diferença textural dos solos, caminhos preferenciais são formados durante o processo geomorfológico de escoamento superficial, fazendo com que, segundo Salomão (2007), os referidos canais, mediante características hidráulicas dos materiais da zona de percolação superficial e subsuperficial; e características do comportamento piezométrico de lençol freático de uma determinada vertente, venham a ocasionar, a partir do contato do corte no relevo com o lençol freático, o surgimento, por exemplo, de feições lineares do tipo voçoroca. Assim, apresenta-se a seguir um setor de voçorocamento (Figura 2) presente na área de estudo, buscando analisa-lo a partir da teoria dos sistemas complexos. 


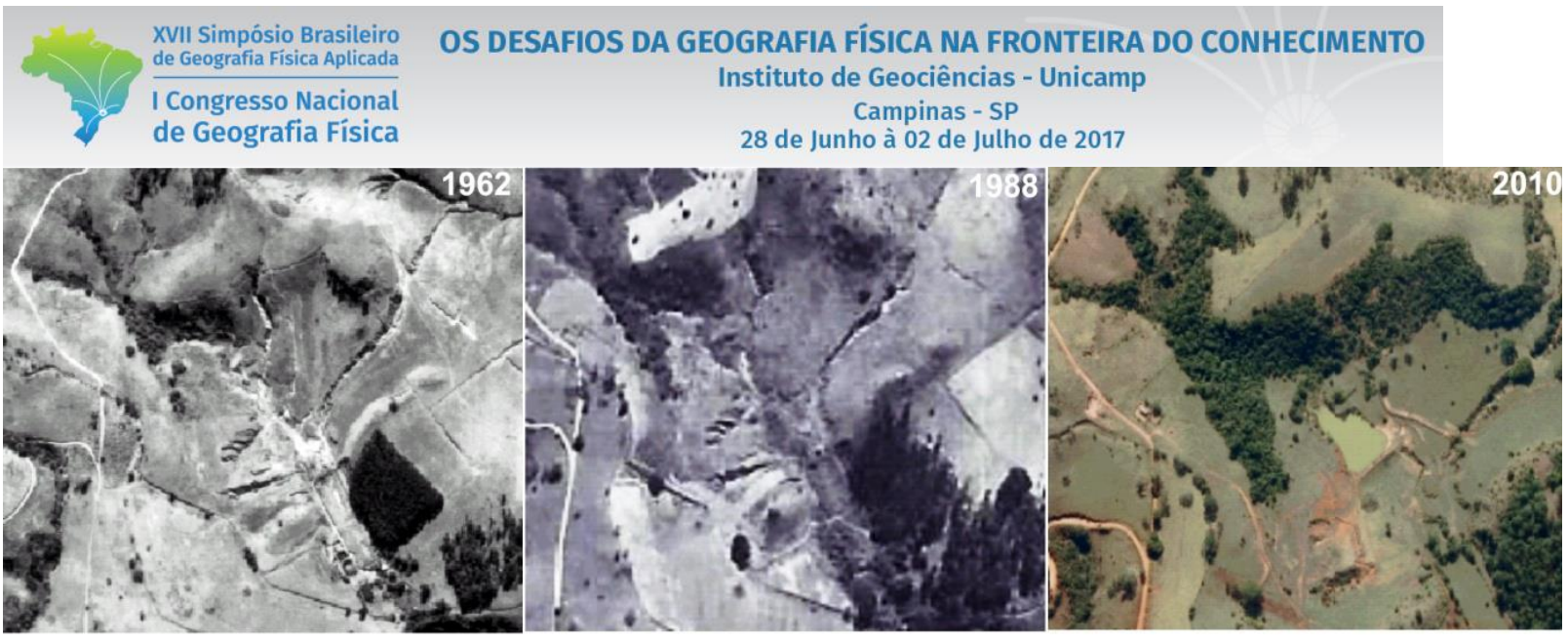

Localização do setor na área de estudo
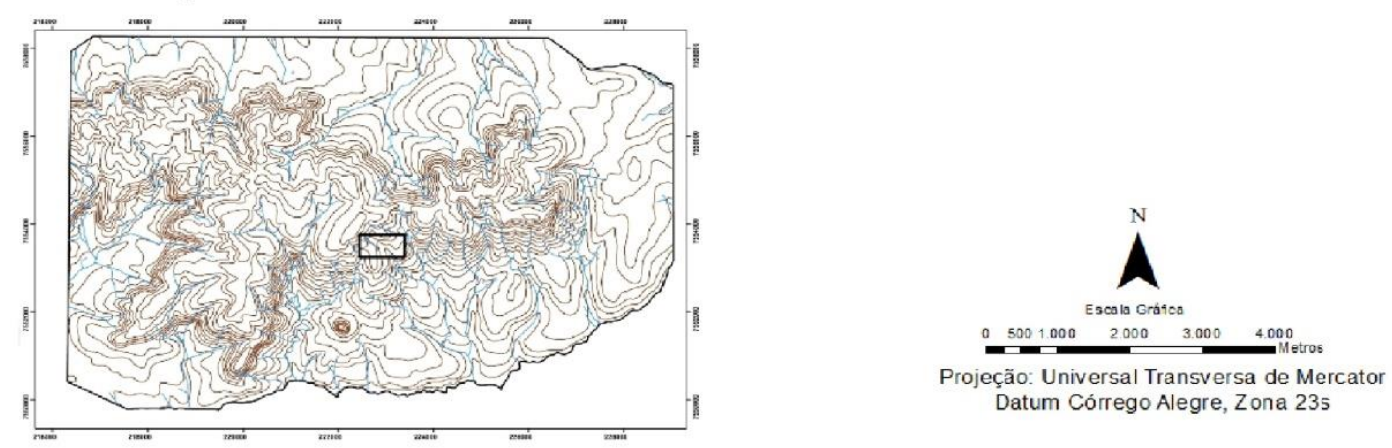

Figura 2 - Análise comparativa da área de ocorrência da Voçoroca Norte.

De acordo com Stefanuto e Lupinacci (2016), a Voçoroca Norte (Figura 2), apresentava no ano de 1962 canais fluviais entalhados e índice de vegetação praticamente nulo. Neste cenário, seu talude erosivo possuía extensão de aproximadamente $500 \mathrm{~m}$. No cenário de 1988, a voçoroca ainda era identificada através de fotointerpretação, apresentando feições erosivas bem demarcadas em seu interior e um pequeno aumento da vegetação em seu entorno. Nesse cenário, segundo Stefanuto e Lupinacci (2016), o talude erosivo da feição linear possuía uma extensão de aproximadamente 560 metros. Por fim, na análise de 2010, os autores atestam a recuperação parcial da área da Voçoroca Norte, uma vez que se identifica um aumento na área vegetada, uma diminuição das feições erosivas identificadas, além da alteração de um curso fluvial, representada pela construção de um lago na área. No cenário de 2010, Stefanuto e Lupinacci (2016), mapeiam este setor apenas com a ocorrência de ravinamentos.

No que concerne ao uso e ocupação da terra no setor de voçorocamento aqui analisado (Gráfico 1), o mesmo apresenta a classe pasto limpo como preponderante nos três cenários, ocupando em 1962, 95,1\% da área; em 1988, 84,8\%; e em 2010 73,2\%. A maior mudança no uso da terra é constatada ao analisar a classe vegetação arbórea que apresenta crescimento contínuo nos três cenários, ocupando em 1962, 2,4\% do setor; em 1988, 13\%; e em 2010, 22\%. Destaca-se também que no último cenário identifica-se um lago, caracterizando a antropização do principal canal fluvial da feição erosiva. 


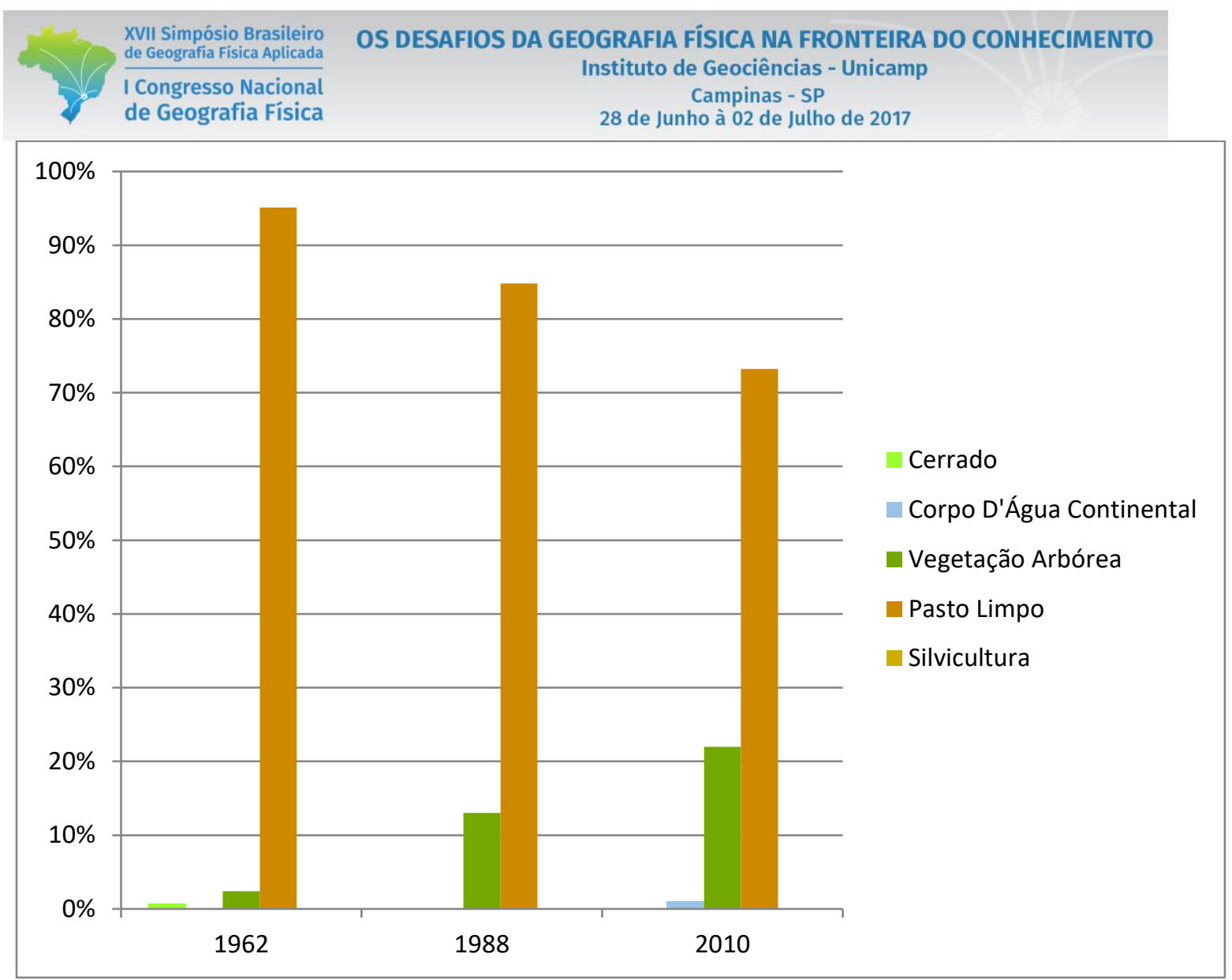

Gráfico 1 - Uso e Ocupação da Terra, em porcentagem, no setor de análise da Voçoroca Norte.

A partir do exposto, compreende-se que na passagem do cenário de 1988 para 2010 o talude erosivo, da até então Voçoroca Norte, deixa de evoluir concomitantemente ao aumento da classe mata e a alteração da drenagem principal. Tais elementos podem ser classificados, de acordo com a proposta de Murray et. al. (2009), como sistemas de forçamento, uma vez que, interrompem a evolução linear do sistema erosivo, fazendo com que respostas não lineares passem a ser emitidas e façam com que a compreensão do referido sistema se torne complexa.

Ao discutir sistemas complexos, outro setor de destaque neste estudo é o front leste da Serra do Cuscuzeiro (Figura 3). Na área, a rede de drenagem apresenta comportamento específico, conforme apresentando na Figura 4. 


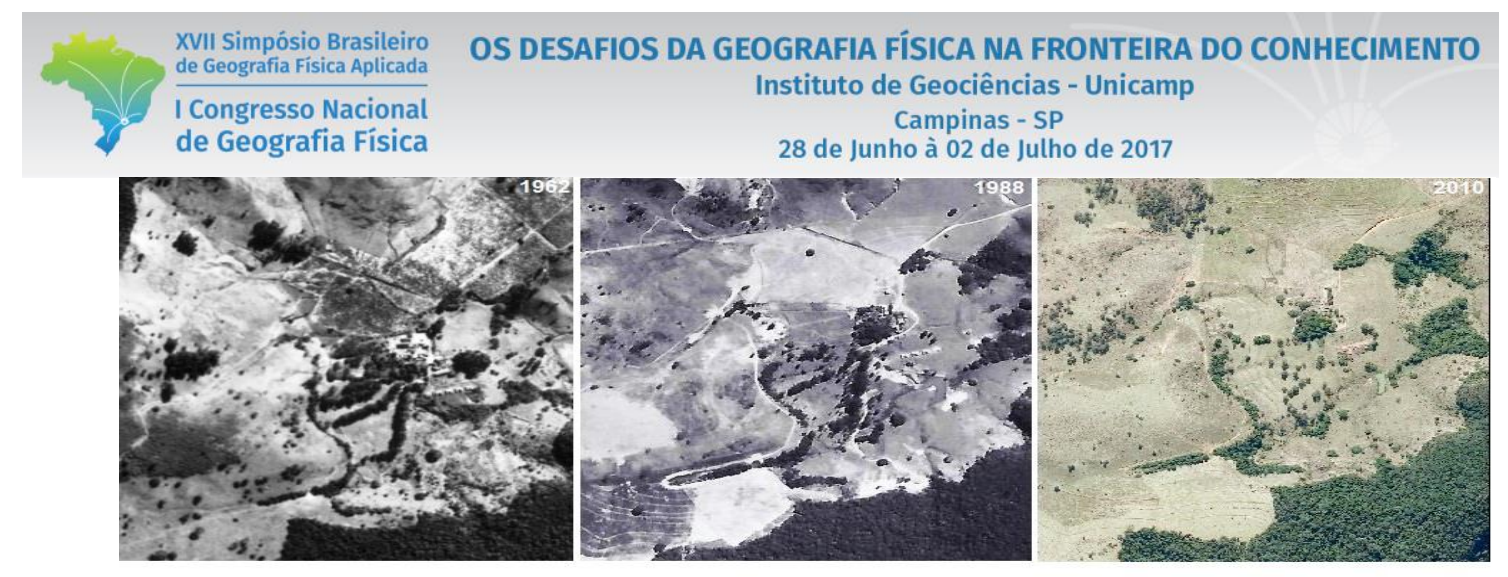

Localização do setor na área de estudo
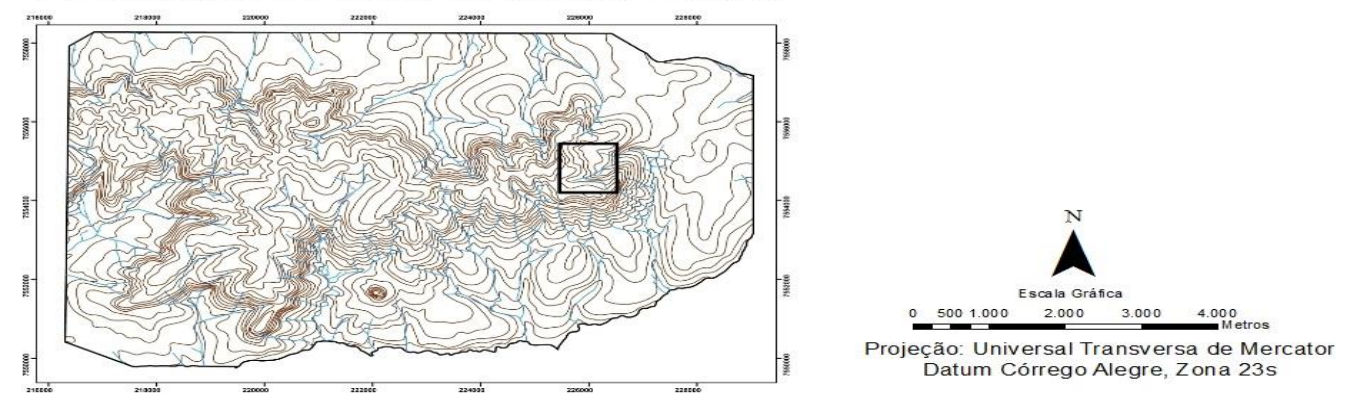

Figura 3 - Setor leste do front da cuesta.
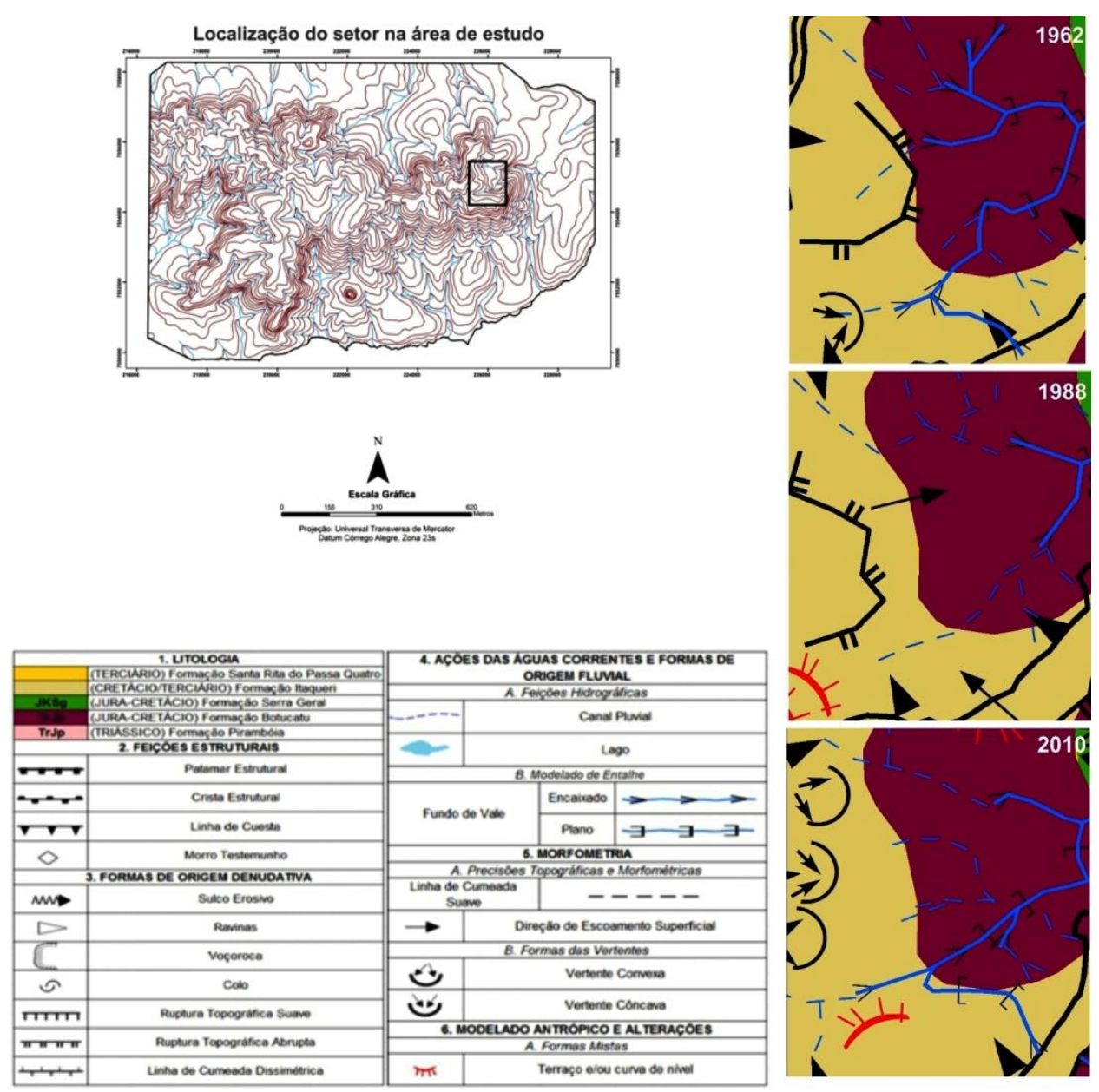

Figura 4 - Alteração no sistema fluvial. 


\section{OS DESAFIOS DA GEOGRAFIA FÍSICA NA FRONTEIRA DO CONHECIMENTO \\ Instituto de Geociências - Unicamp Campinas - SP \\ 28 de Junho à 02 de Julho de 2017}

De acordo com Stefanuto e Lupinacci (2016), assim como o apresentado na Figura 4, constata-se que na transição entre os cenários de 1962 para 1988, há uma expressiva diminuição dos canais fluviais. Já na transição entre 1988 e 2010 alguns córregos ressurgem, mas a área não chega a recuperar todos os canais fluviais que foram registrados em 1962.

No que concerne ao uso da terra (Gráfico 2), o três cenários apresentam a predominância da classe de uso pasto limpo, que ocupa no recorte de 1962, 85,5\% da área; em 1988, 53,4\%; e em 2010, 75,2\%. Deve-se destacar também o expressivo aumento da classe vegetação arbórea, uma vez que em 1962 ocupava uma área de $13 \%$ do setor e em 1988 passa a ocupar 36,8\%, reduzindo, no cenário de 2010, para 24\%. Apresenta ainda um aumento nas lavouras temporárias de $1962(1,5 \%)$ para $1988(8,3 \%)$, ressaltando-se que os setores de ocorrência das lavouras temporárias no cenário de 1988 se desenvolveram sobre áreas de nascentes, identificadas em 1962.

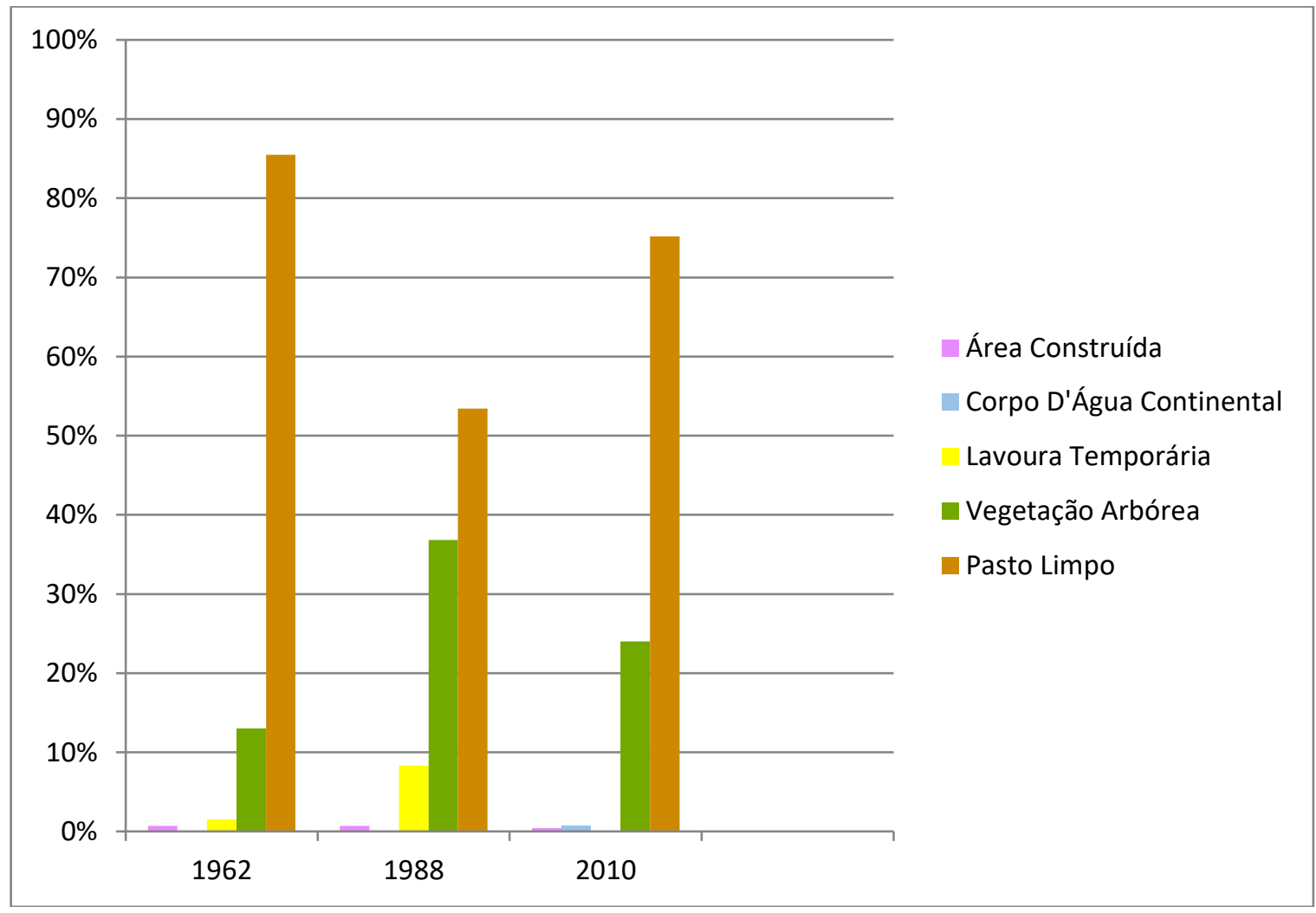

Gráfico 2 - Uso e Ocupação da Terra, em porcentagem, no setor leste do front cuestiforme.

Assim, de acordo com o apresentado, constata-se que os sistemas de forçamento, responsáveis por alterar a densidade de drenagem no setor, podem ser correlacionados com a atuação antrópica através das classes de uso da terra pasto limpo e culturas anuais. As referidas classes fazem com que o sistema emita respostas de forma não linear, uma vez que no período de 1962 a 1988 parte das drenagens tornam-se canais pluviais, mas são reativadas durante o período de 1988 a 2010. Vale destacar também que no espaço de tempo aqui analisado não houve uma congruência entre o aumento da classe de uso vegetação arbórea e a manutenção e/ou o desenvolvimento de novos canais fluviais no setor, 
sendo que no cenário de 1988, no qual a classe de uso vegetação arbórea apresentou crescimento de 30\% em relação ao cenário de 1962, a densidade de drenagem diminuiu drasticamente. Com isso, pode-se atestar a capacidade de alteração no padrão de respostas de um sistema mediante a atuação dos sistemas de forçamento, uma vez que mesmo com o aumento de elementos favoráveis ao desenvolvimento de canais fluviais no cenário de 1988, ocorreu uma diminuição da densidade de drenagem.

\section{Considerações Finais}

$\mathrm{O}$ artigo apresenta o levantamento de hipóteses sobre a atuação de alguns sistemas de forçamento mediante a ação antrópica, estabelecidas através dos cruzamentos de mapeamentos de uso da terra e geomorfológicos, e bibliografias sobre o assunto.

Constatou-se que nos dois setores analisados foram identificados padrões de respostas não lineares, uma vez que, no primeiro setor, o sistema erosivo apresentado deixou de evoluir mediante o aumento da área de vegetação arbórea e alteração, a partir da construção de um lago, no curso fluvial principal. No segundo setor, a rede de drenagem sofreu alterações a partir da instalação de áreas de uso da terra destinadas a lavouras temporárias; assim, apesar do aumento das áreas ocupadas por vegetação arbórea, verificou-se uma influência mais significativa das referidas lavouras uma vez que, no cenário de 1988, a densidade de drenagem diminuiu.

Assim, foi possível verificar que a partir da atuação de sistemas de forçamento de origem antrópica, representados por barramento no curso fluvial e pela implantação de setores de cultivo agrícola, os sistemas analisados exibiram dificuldades em atingirem sua auto-organização, e passaram a emitir respostas não lineares e de difícil previsibilidade pelo ser humano, podendo ser classificados como complexos.

\section{Bibliografia}

AYRES, Q. C. La Erosión del Suelo y su Control. Barcelona: Ediciones Omega S. A., 1960.

CASSETI, V. Ambiente e apropriação do relevo. São Paulo: Contexto, 1991.

CERON, A. O.; DINIZ, J. A. F. O uso das fotografias aéreas na identificação das formas de utilização agrícola da terra. Revista Brasileira de Geografia. n. 2, v. 28, p. 161-173, 1966.

CHAUI, M. Convite à Filosofia. São Paulo: Ática, 1994.

CHRISTOFOLETTI, A.; QUEIROZ NETO J. P. Estudos Geomorfológicos a respeito da Serra de Santana, SP. Boletim Paulista de Geografia. n. 38, p. 3-20, jun/1961.

ELLIS, E. C. Anthropogenic transformation of the terrestrial biosphere. The Royal Society. n. 369, 2011, p. 1010-1035.

HOBSBAWM, E. J. A Era das Revoluções: Europa 1789-1848. Rio de Janeiro: Paz e Terra, 1981.

INSTITUTO BRASILEIRO DE GEOGRAFIA E ESTATÍSTICA. Manual Téenico de Uso da Terra. Rio de Janeiro, 2013. 
MURRAY, A. B et. al. Geomorphology, complexity, and the emerging science of the Earth's suface. Geomorphology. n. 103, 2009. p. 496-505.

NIR, D. Man, a geomorphological agent: an introduction to anthropic geomorphology. Jerusalem: Katem Pub, House, 1983.

PELOGGIA, A. O Homem e o Ambiente Geológico: Geologia, Sociedade e Ocupação Urbana no Município de São Paulo. São Paulo: Xamã, 1998.

PINTON, L. de G. A Antropogeomorfologia na bacia do Córrego do Cavalheiro - Analândia/SP: Uma avaliação da dinâmica de uso da terra e sua adequabilidade a legislação ambiental e a capacidade de uso. 2011. 102 f. Trabalho de Conclusão de Curso - Instituto de Geociência e Ciências Exatas, Universidade Estadual Paulista, Rio Claro, 2011.

SALOMÃO, F. X. T. Controle e prevenção dos processos erosivos. In: GUERRA, A. J. T.; SILVA, A. S.; BOTELHO, R. G. M. (Org.). Erosão e conservação dos solos: conceitos, temas e aplicações. 3 ed. Rio de Janeiro: Bertrand Brasil, 2007. p. 229 e 265.

SOUZA, T. de A. de.; OLIVEIRA, R. C. de. Avaliação da potencialidade de imagens tridimensionais em meio digital para o mapeamento geomorfológico. Revista Geonorte. v. 2, N.4, p.1348-1355, 2012.

STEFANUTO, E. B.; CUNHA, C. M. L. Morfocaracterísticas na faixa de transição Cuesta - Depressão Periférica: Estudo de caso de Analândia (SP). Revista Equador (UFPI). v. 4, n. 3, 2015 a.

STEFANUTO, E. B.; CUNHA, C. M. L. Análise das feições estruturais lineares da Serra do Cuscuzeiro em Analândia (SP). In: CONGRESSO DE INICIAÇÃO CIENTÍFICA DA UNESP. 27. 2015b. Anais...

STEFANUTO, E. B.; LUPINACCI, C. M. A influência antropogênica no relevo do setor cuestiforme de Analândia (SP). In: SIMPÓSIO NACIONAL DE GEOMORFOLOGIA. 11. 2016, Maringá. Anais...

TREWARTHA, G. T. Geografia da população: padrão mundial. Tradução de Veneranda Barreto Hellmeister. São Paulo: Atlas, 1974.

ZALASIEWICZ, $\mathrm{J}$ et. al. The geological cycle of plastics and their use as a stratigraphic indicator of the Anthropocene. Anthropocene. n. 13, 2016. p.4-17. 